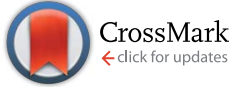

Cite this: RSC Adv., 2016, 6, 95369

Received 25th July 2016

Accepted 30th September 2016

DOI: 10.1039/c6ra18899k

www.rsc.org/advances

\section{Photocatalytic $\mathrm{WO}_{3} / \mathrm{TiO}_{2}$ nanowires: $\mathrm{WO}_{3}$ polymorphs influencing the atomic layer deposition of $\mathrm{TiO}_{2} \uparrow$}

\author{
Dávidné Nagy, ${ }^{\star a b}$ Tamás Firkala, ${ }^{\mathrm{b}}$ Eszter Drotár, ${ }^{c}$ Ágnes Szegedi, ${ }^{c}$ Krisztina László ${ }^{\mathrm{d}}$ \\ and Imre Miklós Szilágyibe
}

50-70 nm hexagonal ( $\mathrm{h}-)$ and 70-90 nm monoclinic (m-) $\mathrm{WO}_{3}$ nanoparticles (NPs) were prepared by controlled annealing of $\left(\mathrm{NH}_{4}\right)_{x} \mathrm{WO}_{3}$ in air at 470 and $600{ }^{\circ} \mathrm{C}$, respectively. In addition, 5-10 nm thick and several micrometer long $\mathrm{h}-\mathrm{WO}_{3}$ nanowires (NWs) were obtained by microwave hydrothermal synthesis at $160{ }^{\circ} \mathrm{C}$ with $\mathrm{Na}_{2} \mathrm{WO}_{4}, \mathrm{HCl}$ and $\left(\mathrm{NH}_{4}\right)_{2} \mathrm{SO}_{4}$ as starting materials. $\mathrm{TiO}_{2}$ was deposited on $\mathrm{h}-\mathrm{WO}_{3} \mathrm{NWs}$ by atomic layer deposition (ALD) at $300{ }^{\circ} \mathrm{C}$ using $\mathrm{Ti}\left({ }^{\prime} \mathrm{OPr}\right)_{4}$ and $\mathrm{H}_{2} \mathrm{O}$ as precursors. The as-prepared materials were studied by TG/DTA-MS, XRD, Raman, SEM-EDX, TEM, ellipsometry, UV-Vis, and their photocatalytic activity was also tested by the photodecomposition of aqueous methyl orange. Our study is the first evidence of diverse ALD nucleation on various $\mathrm{WO}_{3}$ polymorphs, since on $\mathrm{h}-\mathrm{WO}_{3} \mathrm{NWs}^{\mathrm{TiO}} 2$ nucleated only as particles, whereas on $\mathrm{m}-\mathrm{WO}_{3}$ conformal $\mathrm{TiO}_{2}$ film was formed, explained by the different surface $\mathrm{OH}$ coverage of $\mathrm{h}-$ and $\mathrm{m}-\mathrm{WO}_{3}$. The $\mathrm{h}-\mathrm{WO}_{3} \mathrm{NWs}$ had significantly higher photocatalytic activity compared to $\mathrm{h}-\mathrm{WO}_{3} \mathrm{NPs}$, and similar performance as $\mathrm{m}-\mathrm{WO}_{3} \mathrm{NPs}$. By adding $\mathrm{TiO}_{2}$ to $\mathrm{h}-\mathrm{WO}_{3} \mathrm{NWs}$ by ALD method, the photocatalytic performance increased by $65 \%$, showing clearly the uniqueness of ALD to obtain superior oxide composite photocatalysts.

\section{Introduction}

Water scarcity and the purity of available water resources around the world are concerning issues of our century. ${ }^{1,2}$ Semiconductor photocatalysis received substantial attention recently to address environmental remediation challenges such as purifying water sources. $^{3-7}$ It was presented that using solar energy the purification of water is possible from toxic compounds such as certain pharmaceutical drugs, bacteria or herbicids etc. ${ }^{8,9}$ Among semiconductor oxides $\mathrm{TiO}_{2}$ is one of the most studied photocatalyst since its valence and conductance energy levels are suitable for both oxidation and reduction of water molecules (water splitting) ${ }^{\mathbf{1 0 - 1 7}}$ However, the utilization of $\mathrm{TiO}_{2}$ is hugely limited by its restricted light absorption properties to the UV range. Therefore,

${ }^{a}$ Institute for Materials and Processes, School of Engineering, The University of Edinburgh, The King's Buildings, Mayfield Road, Edinburgh, EH9 3JL, UK. E-mail: davidne.nagy@gmail.com

${ }^{b}$ Department of Inorganic and Analytical Chemistry, Budapest University of Technology and Economics, Szent Gellért tér 4., Budapest, H-1111, Hungary

${ }^{c}$ Hungarian Academy of Sciences, Institute of Materials and Environmental Chemistry, Magyar tudósok körútja 2., Budapest, H-1117, Hungary

${ }^{d}$ Department of Physical Chemistry and Materials Science, Budapest University of Technology and Economics, Budafoki út 8., Budapest, H-1111, Hungary

${ }^{e}$ MTA-BME Technical Analytical Research Group of the Hungarian Academy of Sciences, Szent Gellért tér 4., Budapest, H-1111, Hungary

† Electronic supplementary information (ESI) available. See DOI: 10.1039/c6ra18899k besides $\mathrm{TiO}_{2}$, the photocatalytic activity of several other semiconductor oxides was also studied (e.g. $\mathrm{V}_{2} \mathrm{O}_{5}, \mathrm{WO}_{3}, \mathrm{ZnO}$, $\left.\mathrm{ZrO}_{2}\right) \cdot{ }^{18-24}$ Nanostructured $\mathrm{WO}_{3}$ can absorb part of the Visible spectrum, making it the second most studied oxide for visibleresponsive photocatalysis. ${ }^{25}$

Another limiting factor of $\mathrm{TiO}_{2}$ is the relatively fast recombination of the photo-induced charges. One approach to improve the photocatalytic performance of a semiconductor oxide is forming composite photocatalysts with other semiconductors. An important benefit of forming composite nanostructures could be the reduced recombination rate of the photo-generated charges by effective charge transfer between the two semiconductor oxide. In the case of type II band alignment where one of the nanostructure has both the valence and conduction band energies lower positioned than the respective bands of the counterpart effective separation of the charge carriers can take place. ${ }^{26}$ In addition to the production of longer-lived charges, the heterostructure can benefit from Vis activity if a UV active photocatalyst such as $\mathrm{TiO}_{2}$ is coupled with semiconductor oxides absorbing in the visible region. $\mathrm{TiO}_{2} / \mathrm{WO}_{3}$ is such a system and several studies showed that such nanocomposite heterostructures have superior photocatalytic activities over single semiconductors. ${ }^{27-30}$

It is also known that the photocatalytic activity is a complex function of several factors such as the crystal structure, morphology or optical properties of the material etc. ${ }^{31,32}$ In order to achieve high performance photocatalysts maximizing the surface area of the material is a general approach. Therefore, 
several techniques have been adopted to fabricate nanostructured oxide photocatalysts. Among the reported nanostructures, nanofibers have received immense attention due to their high surface-to-volume ratio, good optical, electric and chemical properties. ${ }^{33,34}$

Previous studies revealed that $\mathrm{WO}_{3} / \mathrm{TiO}_{2}$ 1D photocatalysts have huge potential. ${ }^{35-38}$ Unfortunately, $\mathrm{WO}_{3}$ is quite difficult to prepare with very small dimensions. The smallest forms of the most studied $\mathrm{WO}_{3}$ polymorph, i.e. monoclinic (m-) $\mathrm{WO}_{3}$ have been $10-100 \mathrm{~nm}$ as particles, or $50-200 \mathrm{~nm}$ as nanofibers. ${ }^{39-41}$ Nevertheless, $\mathrm{m}-\mathrm{WO}_{3}$ is a widespread photocatalyst. In contrast, the second most important $\mathrm{WO}_{3}$ modification, i.e. hexagonal (h-) $\mathrm{WO}_{3}$, has been studied in photocatalysis only once, and its photocatalytic activity was lower compared to $\mathrm{m}-\mathrm{WO}_{3} \cdot{ }^{42}$ It was explained by that unlike the completely oxidized $\mathrm{m}-\mathrm{WO}_{3}, \mathrm{~h}-\mathrm{WO}_{3}$ always contain some cation (e.g. $\left.\mathrm{Na}^{+}, \mathrm{K}^{+}, \mathrm{NH}_{4}^{+}\right)$impurities in its hexagonal channels, which are vital for stabilizing the metastable structure. ${ }^{\mathbf{4 3 4}}$ Besides, h- $\mathrm{WO}_{3}$ contains also partially reduced $\mathrm{W}$ atoms, which may serve as recombination centers during the photocatalytic reaction, decreasing the activity. ${ }^{43}$ However, $\mathrm{h}-\mathrm{WO}_{3}$ has been prepared recently in the form of very fine nanowires with $c a$. 5-10 $\mathrm{nm}$ thickness, which is a very promising morphology for photocatalysis, but unfortunately their photocatalytic properties have not been tested yet.

Recently it was reported that $\mathrm{m}-\mathrm{WO}_{3} / \mathrm{TiO}_{2}$ core/shell nanofibers, where the shell layer was deposited by atomic layer deposition (ALD), had excellent photocatalytic properties due to the synergy of $\mathrm{WO}_{3}$ and $\mathrm{TiO}_{2} \cdot{ }^{45} \mathrm{ALD}$ is based on successive, alternating surface controlled reactions from the gas phase to produce highly conformal and uniform thin films with thickness control of sub-nanometer precision. Thus, ALD provides new strategies in modifying the properties of nanoscaled materials and new synthetic routes to novel nanostructures. ${ }^{\mathbf{4 6 - 5 2}}$

In the above example the $\mathrm{m}-\mathrm{WO}_{3}$ nanofibers were $200-300$ $\mathrm{nm}$ thick. Thus, it is logical to expect better photocatalytic properties, if $\mathrm{WO}_{3} 1 \mathrm{D}$ nanostructures with even smaller dimensions can be used as substrates. The now available 5-10 $\mathrm{nm}$ thick $\mathrm{h}-\mathrm{WO}_{3}$ fibers are good candidates for employing in $\mathrm{WO}_{3} / \mathrm{TiO}_{2}$ photocatalysts with improved properties.

In this study, we obtained $\mathrm{h}-\mathrm{WO}_{3} \mathrm{NWs}$ by microwave assisted hydrothermal synthesis at $160{ }^{\circ} \mathrm{C}$ with $\mathrm{Na}_{2} \mathrm{WO}_{4}, \mathrm{HCl}$ and $\mathrm{Na}_{2} \mathrm{SO}_{4}$ as starting materials. ALD was the method of choice to put $\mathrm{TiO}_{2}$ onto the $\mathrm{h}-\mathrm{WO}_{3}$ nanowires, since it has the capability to deposit very thin layers on highly structured surfaces. The $\mathrm{TiO}_{2}$ layer was deposited at $300{ }^{\circ} \mathrm{C}$ using $\mathrm{Ti}\left({ }^{\mathrm{i}} \mathrm{OPr}\right)_{4}$ and $\mathrm{H}_{2} \mathrm{O}$ as precursors, and it was designed to have around $3 \mathrm{~nm}$ thickness because previous studies showed that thin $\mathrm{TiO}_{2}$ nanolayers could significantly enhance the photo-efficiency of the nanosized $\mathrm{WO}_{3}{ }^{45}$ It must be noted that up to now ALD growth has been done only on $\mathrm{m}-\mathrm{WO}_{3}$, but not on $\mathrm{h}-\mathrm{WO}_{3}$. Since the two polymorphs have different surface properties, ${ }^{\mathbf{4 2}}$ this allowed us to study the characteristics of ALD nucleation on the surface of various $\mathrm{WO}_{3}$ crystalline structures, which was not yet reported in the literature to the best of our knowledge.

For comparison, we also prepared hexagonal (h-) and monoclinic (m-) $\mathrm{WO}_{3}$ nanoparticles (NPs) by controlled annealing of $\left(\mathrm{NH}_{4}\right)_{x} \mathrm{WO}_{3}$ in air at 470 and $600{ }^{\circ} \mathrm{C}$, respectively. In addition, we prepared an $\mathrm{m}-\mathrm{WO}_{3} / \mathrm{TiO}_{2}$ composite by annealing the $\mathrm{h}-\mathrm{WO}_{3} / \mathrm{TiO}_{2}$ sample at $600{ }^{\circ} \mathrm{C}$ in air. It is well established that at this temperature the $\mathrm{h}-\mathrm{WO}_{3}$ structure transforms into $\mathrm{m}$ $\mathrm{WO}_{3}$. Usually when $\mathrm{m}-\mathrm{WO}_{3}$ is formed thermally from nanostructured precursors, it will be present in the form of 50-200 nm particles. ${ }^{53}$ However, we aimed to test whether the $\mathrm{TiO}_{2}$ coating might prevent the morphology change, and $\mathrm{m}-\mathrm{WO}_{3} /$ $\mathrm{TiO}_{2}$ with nanowire morphology could be obtained.

The obtained materials were studied by TG/DTA-MS, XRD, Raman, SEM-EDX, TEM, ellipsometry, UV-Vis, and their photocatalytic activity was tested by UV-Vis through the photobleaching of aqueous methyl orange.

\section{Experimental}

\section{Preparation methods}

Hexagonal (h-) and monoclinic (m-) $\mathrm{WO}_{3}$ nanoparticles (NPs) were prepared by annealing hexagonal ammonium tungsten bronze, $\left(\mathrm{NH}_{4}\right)_{x} \mathrm{WO}_{3-y}$ in air at $470{ }^{\circ} \mathrm{C}$ and $600{ }^{\circ} \mathrm{C}$, respectively. ${ }^{\mathbf{3 4 , 5 4}}$

For the preparation of $\mathrm{h}-\mathrm{WO}_{3}$ nanowires (NWs) a microwaveassisted hydrothermal synthesis method was applied. ${ }^{44} 1.5 \mathrm{~g}$ $\mathrm{Na}_{2} \mathrm{WO}_{4} \cdot 2 \mathrm{H}_{2} \mathrm{O}$ was dissolved in $33.75 \mathrm{ml} \mathrm{H}_{2} \mathrm{O}$, then under stirring $3.75 \mathrm{ml} 3 \mathrm{M} \mathrm{HCl}$ was added dropwise, and finally 22.5 $\mathrm{ml} 0.5 \mathrm{M}\left(\mathrm{NH}_{4}\right)_{2} \mathrm{SO}_{4}$ was introduced. The as-prepared solution was heated to $160{ }^{\circ} \mathrm{C}$ in $20 \mathrm{~min}$, and then kept at $160^{\circ} \mathrm{C}$ for 3 hours in a Synthos 3000 Anton Paar microwave reactor. The solid reaction product was centrifuged, washed two times with water, once with ethanol, and again two times with water. In each washing step, $45 \mathrm{ml}$ solvent was poured over the crystals; the dispersion was stirred for $1 \mathrm{~min}$, and centrifuged for $5 \mathrm{~min}$ at $6000 \mathrm{~min}^{-1}$. Finally, the as-prepared $\mathrm{h}-\mathrm{WO}_{3} \mathrm{NWs}$ were dried at $80{ }^{\circ} \mathrm{C}$ for 12 hours. The yield was $64 \%$.

The $\mathrm{h}-\mathrm{WO}_{3} / \mathrm{TiO}_{2}$ nanowire composite was prepared by depositing a $\mathrm{TiO}_{2}$ nanolayer onto the surface of the as-prepared $\mathrm{h}-\mathrm{WO}_{3} \mathrm{NWs}$ by atomic layer deposition (ALD). The ALD reaction was carried out at $300{ }^{\circ} \mathrm{C}$ in a Picosun SUNALE R-100 type reactor. $100 \mathrm{ALD}$ cycles were applied using $\mathrm{Ti}\left(\mathrm{O}^{\mathrm{i}} \mathrm{Pr}\right)_{4}\left(60^{\circ} \mathrm{C}\right.$ evaporation temperature) and $\mathrm{H}_{2} \mathrm{O}$ as precursors, with $1 \mathrm{~s}$ pulse and $30 \mathrm{~s}$ purge times for both precursors.

The $\mathrm{m}-\mathrm{WO}_{3} / \mathrm{TiO}_{2}$ composite sample was obtained by annealing the $\mathrm{h}-\mathrm{WO}_{3} / \mathrm{TiO}_{2}$ sample at $600{ }^{\circ} \mathrm{C}$ in air.

\section{Characterization methods}

Thermal analysis was used to investigate the influence of washing steps during the $\mathrm{h}-\mathrm{WO}_{3} \mathrm{NW}$ preparation and to check the thermal stability of as-synthesized h- $\mathrm{WO}_{3} \mathrm{NWs}$. For this an STD 2960 simultaneous TG/DTA device (TA Instruments Inc.) was used, which was on-line coupled to a Thermostar GSD 200 quadruple mass spectrometer (Balzers Instruments) through a heated $\left(200{ }^{\circ} \mathrm{C}\right), 100 \%$ silanated quartz capillary $(D=$ $0.15 \mathrm{~mm}$ ). During the TG/DTA-MS measurements, samples (ca. $100 \mathrm{mg}$ ) were heated in a Pt crucible at $10^{\circ} \mathrm{C} \mathrm{min}{ }^{-1}$ heating rate in flowing air $\left(130 \mathrm{ml} \mathrm{min}^{-1}\right)$. The fragments of the evolved gases were monitored by Multiple Ion Detection (MID) mode in the $1-64 \mathrm{~m} / \mathrm{z}$ range. 
The crystal phases were determined by recording the XRD pattern of the samples by a PANalytical X'pert Pro MPD X-ray diffractometer using $\mathrm{Cu} \mathrm{K} \alpha$ radiation.

The Raman spectra provided further information on the crystal structure and the bonds. A Jobin-Yvon Labram type spectrophotometer equipped with an Olympus BX-41 microscope was used. For excitation source a frequency-doubled $\mathrm{Nd}-$ YAG laser (532 nm) was employed. The scattered photons were collected by a CCD type detector.

To investigate the optical properties of the catalysts, UV-Vis diffuse reflectance spectra were recorded by a Cary 100 UV-Vis spectrophotometer equipped with a DRA-CA-30I type integration sphere.

For the study of the morphology and composition, SEM-EDX and TEM measurements were applied. A LEO 1540XB type RÖNTEC FEG SEM microscope equipped with a Quantax EDX detector was used for the SEM-EDX recordings. The TEM images were provided by a FEI Morgagni 268D type TEM microscope employing a tungsten cathode.

For determining the apparent surface area of the photocatalysts, the BET model was used. The low temperature nitrogen adsorption measurement was conducted in a NOVA $2000 \mathrm{E}$ type (Quantachrome, USA) device at the temperature of liquid nitrogen.

For estimating the ALD $\mathrm{TiO}_{2}$ film thickness, a $\mathrm{TiO}_{2}$ film was deposited on a Si wafer by ALD, using 300 cycles and the same precursors, pulse and purge times, as in the case of $\mathrm{h}-\mathrm{WO}_{3} \mathrm{NW}$ substrates. The film thickness was determined by ellipsometry. The spectra were recorded by a Woollam M-2000DI ellipsometer between 400 and $1500 \mathrm{~nm}$.

\section{Photocatalysis}

The photocatalytic efficiencies of the as-prepared catalysts were tested in the photo-bleaching reaction of methyl-orange (MO). The concentration of the catalyst and the methyl orange were 100 $\mathrm{mg} / 350 \mathrm{ml}$ and $10 \mathrm{mg} / 350 \mathrm{ml}$, respectively. A Heraus TQ 150 mercury immersion lamp (radiation flux, $\Phi: 200-600 \mathrm{~nm} 47 \mathrm{~W}$, strongest spectral lines: $254 \mathrm{~nm}$ : $4 \mathrm{~W}, 313 \mathrm{~nm}: 4.3 \mathrm{~W}, 366 \mathrm{~nm}: 6.4$ $\mathrm{W}, 405 \mathrm{~nm}: 3.2 \mathrm{~W}, 436 \mathrm{~nm}: 4.2 \mathrm{~W}, 546 \mathrm{~nm}: 5.1 \mathrm{~W}, 577 \mathrm{~nm}: 4.7 \mathrm{~W})$ was applied in a Heraus type cylindrical glass photo-reactor. The experiments were conducted under oxygen bubbling at room temperature assured by the continuous water circulation through the cooling jacket of the lamp. At first the solution was kept in dark for $15 \mathrm{~min}$, to reach the adsorption equilibrium between the catalyst and the dye. Then the lamp was switched on and $3 \mathrm{ml}$ samples were taken in every $30 \mathrm{~min}$ using a syringe equipped with filter (Sigma Aldrich, Iso-Disc, PTFE, $0.45 \mu \mathrm{m}$ pore size membrane). The decline of the MO concentration was followed by a Jasco V-550 type UV-Vis spectrophotometer at $465 \mathrm{~nm}$.

\section{Results and discussion}

\section{Formation mechanism of $\mathbf{h}-\mathrm{WO}_{3}$ nanowires}

The fabrication of nano-sized $\mathrm{WO}_{3}$ by wet-chemical synthesis approaches such as hydrothermal (HT) synthesis is a popularly applied method for cheap and versatile nanostructure formulation. ${ }^{\mathbf{4 4 5 5}}$ To direct crystal growth in HT synthesis various structure directing agents were presented in the literature from simple inorganic salts like $\mathrm{Na}_{2} \mathrm{SO}_{4}, \mathrm{NH}_{4} \mathrm{NO}_{3}$ to complex organic structures like oxalic acid or poly-ethylene glycol. ${ }^{33,55,56}$ To fabricate delicate $\mathrm{h}-\mathrm{WO}_{3}$ nanowires in this paper $\left(\mathrm{NH}_{4}\right)_{2} \mathrm{SO}_{4}$ was used following an earlier report. ${ }^{44}$ It is believed that the capping agents such as $\left(\mathrm{NH}_{4}\right)_{2} \mathrm{SO}_{4}$ dictate anisotropic $1 \mathrm{D}$ growth by selectively binding to specific crystal facets of the initial crystal nuclei of $\mathrm{WO}_{3}$. The adsorption of capping agents increases the surface energy of the selected facets leading to inhibited crystal growth rates and resulting in the formation of $1 \mathrm{D}$ nanostructures. ${ }^{44}$ It is also known that several other factors may contribute to the morphology and crystal phases of the final nanomaterials such as time, temperature or the $\mathrm{pH} .^{31,55,57}$ This latter one plays an especially important role in the formation of $\mathrm{WO}_{3}$ since $\mathrm{H}^{+}$is essential to form tungstic acid from the selected tungsten precursor which is typically a tungstate. Then $\mathrm{WO}_{3}$ is formed according to eqn (1).

$$
\mathrm{WO}_{4}{ }^{2-}+2 \mathrm{H}^{+} \leftrightarrow \mathrm{H}_{2} \mathrm{WO}_{4} \stackrel{T\left({ }^{\circ} \mathrm{C}\right)}{\longrightarrow} \mathrm{WO}_{3}+\mathrm{H}_{2} \mathrm{O}
$$

\section{Thermal analysis}

The role of washing steps in reaching pure $\mathrm{h}-\mathrm{WO}_{3}$ nanowires after the microwave hydrothermal reactions was studied by TG/ DTA-MS measurement. The results (presented in detail in the ESI $\dagger$ ) confirmed that washing steps were effective and removed all precursors and reactants. The as-prepared, non-washed, only dried h- $\mathrm{WO}_{3} \mathrm{NW}$ samples contained significant amount from not used reagents, i.e. $\left(\mathrm{NH}_{4}\right)_{2} \mathrm{SO}_{4}, \mathrm{HCl}$, and water as well, from which various gaseous products were detected in air, e.g. $\mathrm{H}_{2} \mathrm{O}$, $\mathrm{NH}_{3}$, from the decomposition of $\mathrm{NH}_{4}{ }^{+}$, $\mathrm{NO}$ and $\mathrm{N}_{2} \mathrm{O}$ from the combustion of $\mathrm{NH}_{3}, \mathrm{HCl}, \mathrm{SO}$ and $\mathrm{SO}_{2}$ from the decomposition of $\mathrm{SO}_{4}{ }^{2-}$ (ref. 58) (Table $\mathrm{S} 1 \dagger$ ). When the sample was annealed, until $100{ }^{\circ} \mathrm{C}$ small amount of adsorbed $\mathrm{H}_{2} \mathrm{O}$ was released in an endothermic reaction (Fig. S1 and $\mathrm{S} 2 \dagger$ ). Then between 150-300 ${ }^{\circ} \mathrm{C}_{2} \mathrm{O}$ and $\mathrm{NH}_{3}$ evolved accompanied by an endothermic heat effect, whereas between 300-450 ${ }^{\circ} \mathrm{C} \mathrm{H}_{2} \mathrm{O}, \mathrm{NH}_{3}, \mathrm{NO}_{x}$ and $\mathrm{SO}_{x}$ gases were detected. The combustion of $\mathrm{NH}_{3}$ was an endothermic reaction, which changed the DTA curve to endothermic. ${ }^{59} \mathrm{HCl}$ was released above $450{ }^{\circ} \mathrm{C}$, accompanied by further release of $\mathrm{SO}_{2}$.

After the washing steps (Fig. S3 and $\mathrm{S} 4 \dagger$ ), all impurities were removed, and accordingly the total mass loss until $900{ }^{\circ} \mathrm{C}$ decreased from $18.2 \%$ to $5.8 \%$. Now only the release of water was observed in two endothermic reactions between 25-200 and 200-450 ${ }^{\circ} \mathrm{C}$. The metastable hexagonal $\mathrm{WO}_{3}$ framework was transformed into the thermodynamically stable $\mathrm{m}-\mathrm{WO}_{3}$ at $503{ }^{\circ} \mathrm{C}$ in an exothermic reaction. The results confirmed the importance of proper washing steps after the microwave hydrothermal reaction in order to obtain pure $\mathrm{h}-\mathrm{WO}_{3}$ nanowires. The thermal analysis also showed that the cleaned, pure $\mathrm{h}-\mathrm{WO}_{3}$ was stable until $500{ }^{\circ} \mathrm{C}$, therefore performing the ALD reaction at $300{ }^{\circ} \mathrm{C}$ was safe.

After the ALD reaction performed at $300{ }^{\circ} \mathrm{C}$-on and $10^{3} \mathrm{~Pa}$ vacuum the $\mathrm{h}-\mathrm{WO}_{3} \mathrm{NWs}$ lost considerable amount of adsorbed 
and structural water (only $2.5 \%$ mass loss) (Fig. S6 and S7 $\dagger$ ). The exothermic DTA peak belonging to the hexagonal-monoclinic $\mathrm{WO}_{3}$ transformation was at $506{ }^{\circ} \mathrm{C}$.

\section{XRD}

The XRD patterns (Fig. 1) served information about the crystalline structure of the samples. No crystalline impurities were detected in any of the samples. All reflection peaks of $\mathrm{h}-\mathrm{WO}_{3}$ NPs were assigned to pure h-WO $\mathrm{WO}_{3}$ (ICDD 33-1387). The h- $\mathrm{WO}_{3}$ NWs exhibited well-defined and intense diffraction peaks supposing high crystallinity of the sample. The crystalline phase was confirmed to be pure $\mathrm{h}-\mathrm{WO}_{3}$. The XRD pattern of $\mathrm{m}$ $\mathrm{WO}_{3}$ NPs was interpreted as pure monoclinic $\mathrm{WO}_{3}$ (ICDD 431035).

In the diffraction pattern of $\mathrm{h}-\mathrm{WO}_{3} / \mathrm{TiO}_{2}$ nanocomposite (Fig. 1) only the $\mathrm{h}-\mathrm{WO}_{3}$ phase could be identified (ICDD 331387). The characteristic reflections of $\mathrm{TiO}_{2}$ could not be detected in the XRD pattern due to the very thin $\mathrm{TiO}_{2}$ layer (aimed to be less than $3 \mathrm{~nm}$ ).

\section{Raman}

The crystalline phases of the as-prepared $\mathrm{WO}_{3}$ nanostructures were confirmed by their Raman spectra as well (Fig. 2), in agreement with the XRD results. The $\mathrm{h}-\mathrm{WO}_{3} \mathrm{NPs}$ showed welldefined bands characteristic of $\mathrm{h}-\mathrm{WO}_{3}$. The most intense peak at $785 \mathrm{~cm}^{-1}$ along with the bands at 650 and $691 \mathrm{~cm}^{-1}$ can be associated with the stretching vibration modes of $(\mathrm{O}-\mathrm{W}-\mathrm{O}){ }^{6 \mathbf{6 0}, \mathbf{6 1}}$ The bands at 263 and $320 \mathrm{~cm}^{-1}$ can be assigned to bending vibrations of $\mathrm{W}-\mathrm{O}-\mathrm{W}$, whereas at $186 \mathrm{~cm}^{-1}$ the lattice vibration mode can be found. ${ }^{\mathbf{6 0 , 6 2}}$

The Raman spectrum of $\mathrm{h}-\mathrm{WO}_{3}$ NWs was substantially different from that of the $\mathrm{h}-\mathrm{WO}_{3} \mathrm{NPs}$. One of the deviances was that the $\mathrm{h}-\mathrm{WO}_{3} \mathrm{NW}$ exhibited overlapping bands in the region of 600 and $850 \mathrm{~cm}^{-1}$. Another considerable difference was that exclusively in the Raman spectra of $\mathrm{h}-\mathrm{WO}_{3} \mathrm{NWs}$ terminal $\mathrm{W}=\mathrm{O}$ stretching modes were recognizable in the interval of 925-965 $\mathrm{cm}^{-1}{ }^{60,63-65}$ These peaks are common for all types of $\mathrm{WO}_{3}$ hydrates, and in some cases the appearance of these

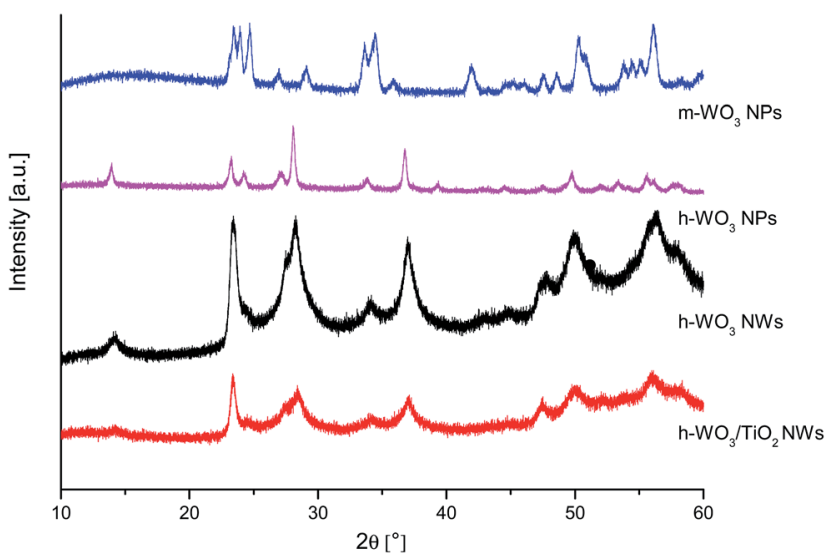

Fig. 1 Powder diffraction pattern of the $\mathrm{m}-\mathrm{WO}_{3} \mathrm{NPs}, \mathrm{h}-\mathrm{WO}_{3} \mathrm{NPs}, \mathrm{m}-$ $\mathrm{WO}_{3} \mathrm{NWs}$, and $\mathrm{h}-\mathrm{WO}_{3} / \mathrm{TiO}_{2} \mathrm{NWs}$ samples.

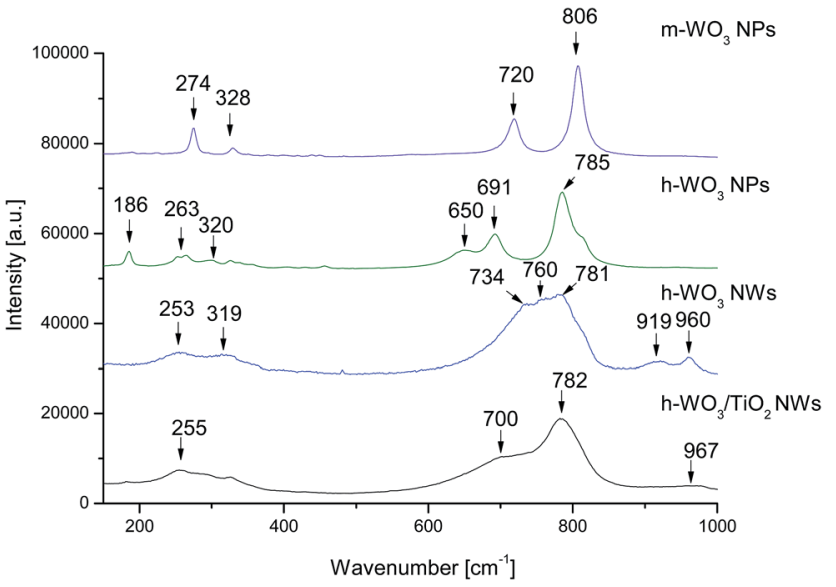

Fig. 2 Raman spectra of the $\mathrm{m}-\mathrm{WO}_{3} \mathrm{NPs}, \mathrm{h}-\mathrm{WO}_{3} \mathrm{NPs}, \mathrm{m}-\mathrm{WO}_{3} \mathrm{NWs}$, and $\mathrm{h}-\mathrm{WO}_{3} / \mathrm{TiO}_{2} \mathrm{NWs}$ samples.

bands were attributed to surface humidity. ${ }^{43}$ The absence of these bands in the spectra of $h$ - and $m-\mathrm{WO}_{3}$ NPs can be ascribed to the high temperature treatment at 500 and $650{ }^{\circ} \mathrm{C}$, respectively. Santato et al. reported that the $\mathrm{W}=\mathrm{O}$ stretching modes in the latter wavenumber interval gradually disappeared by applying increasing annealing temperature in the synthesis process. ${ }^{63}$

The Raman bands of $\mathrm{m}-\mathrm{WO}_{3}$ NPs were in good correspondence with literature values. ${ }^{66}$ The peaks were sharp and welldeveloped supposing good crystallinity of the sample. The bands positioned at 806 and $720 \mathrm{~cm}^{-1}$ can be assigned to stretching $(\mathrm{O}-\mathrm{W}-\mathrm{O})$ vibrational modes. The bands at lower wavelength values belong to $(\mathrm{O}-\mathrm{W}-\mathrm{O})$ deformation modes. ${ }^{60}$

The Raman bands of $\mathrm{h}-\mathrm{WO}_{3} / \mathrm{TiO}_{2}$ nanocomposite (Fig. 2) were broadened, compared to $\mathrm{h}-\mathrm{WO}_{3} \mathrm{NWs}$. Probably during the ALD deposition some partially reduced $\mathrm{W}$ atoms were produced, either due to the conditions $\left(300{ }^{\circ} \mathrm{C}, 10^{3}\right.$ Pa vacuum) or to the reaction between the precursors and the substrate, and therefore the structure became less ordered. The Raman spectrum is sensitive to the different oxidation states of the atoms due to the change of the chemical bond strength, which resulted in a small shift of the peak positions involving $\mathrm{W}$ atoms of different oxidations states. ${ }^{42}$ In the $\mathrm{h}-\mathrm{WO}_{3} / \mathrm{TiO}_{2}$ sample the bands involving completely oxidized $(+6)$ and partially reduced $(+5,+4) \mathrm{W}$ atoms overlapped, making the peaks broader. The presence of partially reduced tungsten atoms was also indicated by the color change of the sample (it became blue) and by its optical behavior, discussed later. In addition, the terminal $\mathrm{W}=\mathrm{O}$ stretching modes (above $900 \mathrm{~cm}^{-1}$ ) of the $\mathrm{h}-\mathrm{WO}_{3} / \mathrm{TiO}_{2}$ nanocomposite had much lower intensities compared to the substrate $\mathrm{h}-\mathrm{WO}_{3} \mathrm{NW}$. The occurred ALD nucleation and the applied temperature and pressure could be accounted for the reduced band intensities.

Characteristic bands of $\mathrm{TiO}_{2}$ could not be observed as the bands of $\mathrm{TiO}_{2}$ usually become perceptible above $10 \mathrm{~nm}$ film thickness. ${ }^{45}$ Similar findings were made by others who found that $1-5 \% \mathrm{WO}_{3}$ loading in a $\mathrm{WO}_{3} / \mathrm{TiO}_{2}$ nanostructure did not show bands for $\mathrm{WO}_{3}$ due to low content of $\mathrm{WO}_{3} \cdot{ }^{67}$ 


\section{SEM-EDX, TEM}

Fig. 3 shows the SEM and TEM images of the prepared catalyst. It was found that the h-WO $\mathrm{WP}_{3}$ NPs (Fig. $3 \mathrm{a}$ and b) consisted of 50$70 \mathrm{~nm}$ nanocrystals. The SEM and TEM images confirmed the formation of uniform and good quality nanowires for the h- $\mathrm{WO}_{3}$ NWs (Fig. 3c and d) being several micrometer long and ca. 5$10 \mathrm{~nm}$ thick. On Fig. 3e and $\mathrm{f}$ the $\mathrm{m}-\mathrm{WO}_{3}$ NPs can be viewed, consisting of irregularly-shaped nanoparticles with a characteristic dimension of 60-90 $\mathrm{nm}$.

The EDX elemental analysis revealed that h- $\mathrm{WO}_{3} \mathrm{NWs}$ contained 2.82 atom\% of $\mathrm{Na}$ beside $\mathrm{W}$ and $\mathrm{O}$ atoms, which can be attributed to stabilizing $\mathrm{Na}$ ions in the hexagonal channels. ${ }^{43}$

SEM-EDX results were also obtained about the effectiveness of the washing steps. On the SEM image of the as-prepared, non-washed, dried h- $\mathrm{WO}_{3} \mathrm{NW}$ sample micrometer scale particles of the not used reactants can be also seen, and EDX analysis confirmed the presence of $\mathrm{N}, \mathrm{Cl}$ and $\mathrm{S}$, besides $\mathrm{O}, \mathrm{Na}$ and $\mathrm{W}$ (Fig. S5†).

In the $\mathrm{h}-\mathrm{WO}_{3} / \mathrm{TiO}_{2}$ NWs the SEM and TEM images (Fig. 4a and b) revealed that the $\mathrm{TiO}_{2}$ was successfully deposited onto the surface of $\mathrm{h}-\mathrm{WO}_{3}$ NWs in the form of individual nanoparticles. The $\mathrm{TiO}_{2}$ nanoparticles had the diameter of around 5-10 nm, which corresponds to double thickness obtained by ellipsometry data, and is rationalized by the $3 \mathrm{D}$ growth of the $\mathrm{TiO}_{2}$ particles. This is in agreement with expectations, as in the case of nanoparticle nucleation a 3D ALD growth is taking place. EDX showed 2.64 atom $\% \mathrm{Ti}$ in the $\mathrm{h}-\mathrm{WO}_{3} / \mathrm{TiO}_{2}$ sample, and confirmed the successful deposition of $\mathrm{TiO}_{2}$ onto the h- $\mathrm{WO}_{3} \mathrm{NWs}$.

It was also investigated whether an $\mathrm{m}-\mathrm{WO}_{3} / \mathrm{TiO}_{2}$ composite with nanowire morphology could be obtained by annealing the h- $\mathrm{WO}_{3} / \mathrm{TiO}_{2}$ sample. According to SEM and TEM images (Fig. 4c
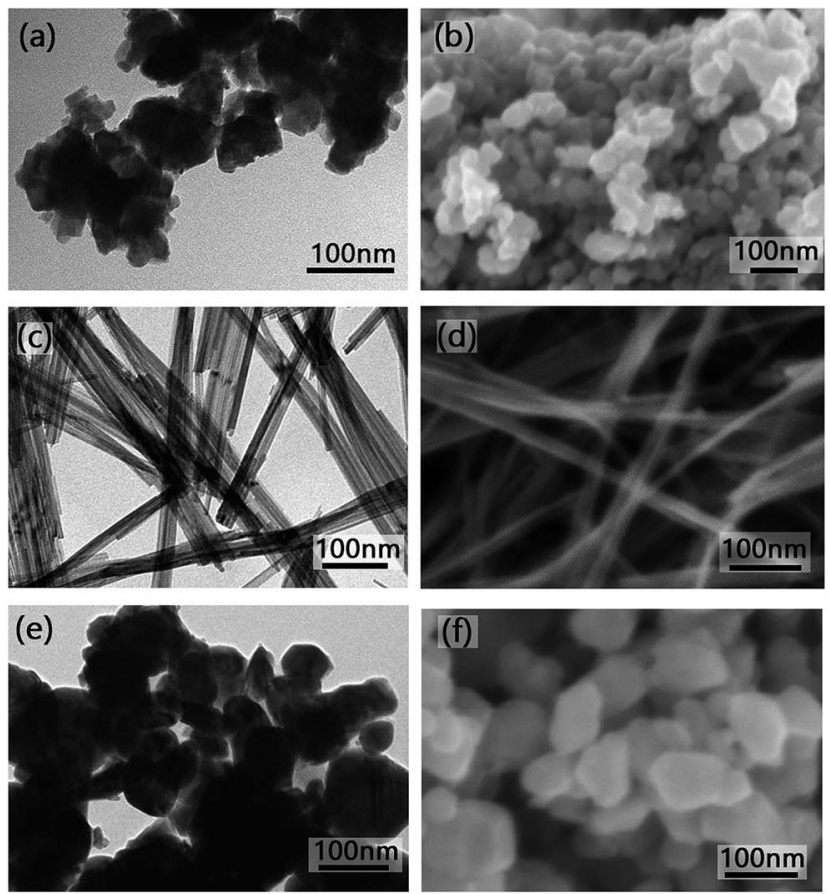

Fig. 3 TEM and SEM images, respectively, of the prepared samples (a, b) $\mathrm{h}-\mathrm{WO}_{3} \mathrm{NPs}$, (c, d) h-WO $\mathrm{WWs}_{3} \mathrm{~N}, \mathrm{e}$ ) $\mathrm{m}-\mathrm{WO}_{3} \mathrm{NPs}$.
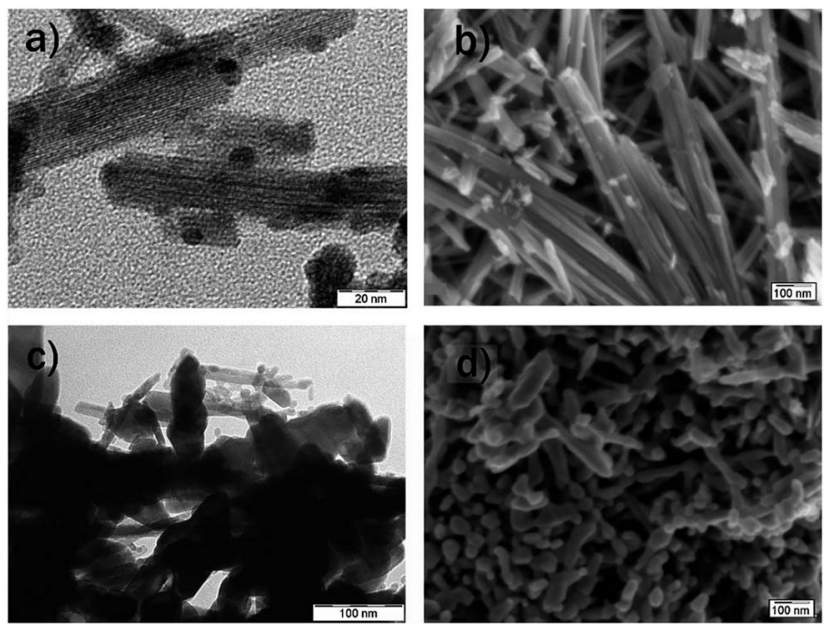

Fig. 4 TEM and SEM images of the ( $\mathrm{a}$ and $\mathrm{b}$ ) $\mathrm{h}-\mathrm{WO}_{3} / \mathrm{TiO}_{2} \mathrm{NWs}$ catalyst, (c and d) $\mathrm{m}-\mathrm{WO}_{3} / \mathrm{TiO}_{2}$ samples obtained by annealing $\mathrm{h}-\mathrm{WO}_{3} / \mathrm{TiO}_{2}$ NWs.

and d), the fine nanowire morphology was lost when h- $\mathrm{WO}_{3}$ transformed into $\mathrm{m}-\mathrm{WO}_{3}$. In the $\mathrm{m}-\mathrm{WO}_{3} / \mathrm{TiO}_{2}$ composite $\mathrm{m}$ $\mathrm{WO}_{3}$ was present in the form of $30-50 \mathrm{~nm}$ particles, some of them being connected to each other in a line, pointing to their $\mathrm{h}-\mathrm{WO}_{3}$ nanowire origin. The $\mathrm{TiO}_{2}$ could be observed as $10 \mathrm{~nm}$ particles on the surface of $\mathrm{m}-\mathrm{WO}_{3}$.

\section{Apparent surface area}

The BET nitrogen adsorption measurements were carried out to compare the surface area of the synthesized $\mathrm{WO}_{3}$ nanostructures. For $\mathrm{h}-\mathrm{WO}_{3} \mathrm{NPs}$ it was found to be $11 \mathrm{~m}^{2} \mathrm{~g}^{-1} \cdot{ }^{68}$ Whereas the $\mathrm{h}-\mathrm{WO}_{3} \mathrm{NWs}$ exhibited a much higher surface area of $101 \mathrm{~m}^{2} \mathrm{~g}^{-1}$ which is in good agreement with earlier literature results. ${ }^{44}$ The almost an order of magnitude higher surface area of the $\mathrm{h}-\mathrm{WO}_{3} \quad \mathrm{NWs}$ relative to the $\mathrm{h}-\mathrm{WO}_{3}$ NPs showed the significant effect of the morphology in the surface area which is considered to be an important factor in photocatalysis. The BET surface area of $\mathrm{m}-\mathrm{WO}_{3}$ nanostructure was found to be the lowest among the $\mathrm{WO}_{3}$ nanostructures with $6.5 \mathrm{~m}^{2} \mathrm{~g}^{-1} .^{42}$

\section{Ellipsometry}

The estimation of the equivalent $\mathrm{TiO}_{2}$ layer thickness was determined by ellipsometry on a reference Si wafer. As the native oxide layer on the Si wafer is approximately $3 \mathrm{~nm}$ thick, three times more ALD cycle (300 ALD cycle) were run under the same condition on the reference wafer than during the preparation of the nanocomposite in order to make the estimation more accurate. The approximated equivalent $\mathrm{TiO}_{2}$ thickness prepared by 100 ALD cycles was calculated as $3.65 \mathrm{~nm}$.

\section{ALD nucleation determined by the surface properties of $\mathrm{WO}_{3}$ polymorphs}

Based on SEM and TEM results, it was found that the $\mathrm{TiO}_{2}$ nucleation followed a distinct pattern on $\mathrm{WO}_{3}$ polymorphs. Earlier it was reported that the ALD-deposited $\mathrm{TiO}_{2}$ formed 
a continuous layer on the surface of electrospun $\mathrm{m}-\mathrm{WO}_{3}$ nanofibers resulting in a core-shell nanocomposite. ${ }^{45}$ Our results revealed that for $\mathrm{h}-\mathrm{WO}_{3}$ nanowires, instead of a continuous layer, the deposited $\mathrm{TiO}_{2}$ formed nanoparticle islands. The surface chemistry of the nanostructures plays a key role in the ALD reaction as the native functional group coverage on the surface serves as first binding sites for the ALD reaction. ${ }^{69-71}$ Most probably, the distinct ALD nucleation could be accounted for the different surface $\mathrm{OH}^{-}$group density of the $\mathrm{WO}_{3}$ polymorphs. Szilágyi et al. reported that based on the XPS spectra the amount of surface $\mathrm{OH}^{-}$group was $0.52 \%$ for the $\mathrm{h}-\mathrm{WO}_{3} \mathrm{NPs}$ and $0.70 \%$ for $\mathrm{m}-\mathrm{WO}_{3}$ NPs. ${ }^{42}$ The nucleation of $\mathrm{TiO}_{2}$ nanoparticles on the surface of $\mathrm{h}-\mathrm{WO}_{3}$ as opposed to continuous film construction, is probably due to the less available nucleation sites.

\section{UV-Vis absorption}

All $\mathrm{WO}_{3}$ nanostructures regardless of the crystal phase exhibited pale yellow colour, however it was found that $\mathrm{h}-\mathrm{WO}_{3} / \mathrm{TiO}_{2} \mathrm{NWs}$ nanocomposite turned into blue after the ALD reaction. Solid phase UV/Vis diffuse reflectance (DR) spectra were recorded and analyzed to reveal the optical behavior of the nanostructures and help to understand the reason for the colour differences. The DR spectra is shown in Fig. 5.

It was observed that the $\mathrm{h}-\mathrm{WO}_{3}$ NWs and NPs exhibited a sharp drop of the absorption around $460 \mathrm{~nm}$ and $478 \mathrm{~nm}$ respectively. Similarly, $\mathrm{m}-\mathrm{WO}_{3}$ NPs showed an absorption threshold at about $485 \mathrm{~nm}$. These values are typical band edges for nanostructured $\mathrm{WO}_{3}{ }^{56,72}$ It is believed that $\mathrm{h}-\mathrm{WO}_{3}$ nanostructures typically exhibit higher energy band values (therefore appears at lower wavelength) due to structural differences. ${ }^{73}$

For the $\mathrm{h}-\mathrm{WO}_{3} / \mathrm{TiO}_{2}$ nanocomposite it was noted that although $\mathrm{TiO}_{2}$ has a typical absorption threshold around 390$410 \mathrm{~nm},{ }^{74}$ the nanocomposite still exhibited absorption in the whole Vis range. Presumably, the enhanced visible absorption arose from the newly generated in-gap states in the band gap

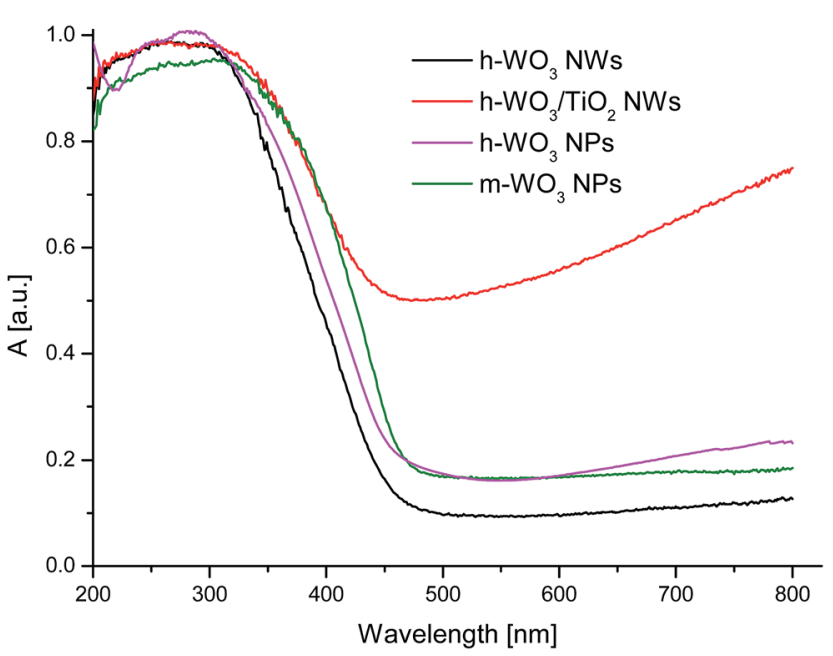

Fig. 5 UV-Vis diffuse reflectance spectra of $\mathrm{h}-\mathrm{WO}_{3} \mathrm{NWs}$, $\mathrm{h}-\mathrm{WO}_{3} \mathrm{NPs}$, $\mathrm{m}-\mathrm{WO}_{3} \mathrm{NPs}$ and $\mathrm{h}-\mathrm{WO}_{3} / \mathrm{TiO}_{2} \mathrm{NWs}$ samples. due to the presence of partially reduced $\mathrm{W}$ atoms. The reduced W atoms were indicated by Raman spectroscopic results and it is believed to be caused by the high temperature and vacuum used over the course of ALD reaction. The blue appearance of the sample is also an indication of the presence of in-gap states in the far-red region of the visible spectrum.

\section{Photocatalysis}

The photo-efficiency of the catalysts was modelled in the photobleaching reaction of methyl orange under UV-Vis light irradiation (Fig. 6). The relative absorbance was calculated and plotted against time to follow the dye degradation (see on Fig. 6a). Additionally, first-order kinetics could be used to describe the behavior of our data which can be expressed in the following form:

$$
\ln \left(\frac{C}{C_{0}}\right)=k t
$$

where $C$ is the dye concentration, $C_{0}$ is the initial dye concentration, $k$ is the first-order rate constant and $t$ is time. To test the repeatability of the photocatalytic results multiple experiments were performed. It was found that the experimental error has never exceeded $\pm 4 \%$ and was typically $2-3 \%$. The effect of photolysis was negligible under the experimental conditions. The catalysts after the photocatalytic test did not show any visible change e.g. in their color.

It was found that the nanowire morphology could enhance significantly the photoactivity of $\mathrm{h}-\mathrm{WO}_{3} \mathrm{NWs}$. Compared to the reference $\mathrm{h}-\mathrm{WO}_{3} \mathrm{NPs}$, the $\mathrm{h}-\mathrm{WO}_{3}$ NWs photo-bleached more than twice as much dye within 4 hours. The enhanced efficiency was reflected on the first-order rate constant values as well, exhibiting $1.72 \times 10^{-3} \mathrm{~min}^{-1}$ and $4.93 \times 10^{-4} \mathrm{~min}^{-1}$, respectively. It is generally expected that $1 \mathrm{D}$ nanostructures could improve the photocatalytic performance by providing enhanced charge carrier properties and therefore reduced charge recombination. ${ }^{75}$ However, in some cases it was revealed that other factors such as the oxidation state of the $\mathrm{WO}_{3}$ could significantly reduce the photo-bleaching performance despite the $1 \mathrm{D}$ morphology. ${ }^{31}$ Our results confirmed that there was no such inhibiting factor therefore the nanowire morphology provided an enhanced efficiency over the nanoparticle morphology in the photocatalytic test.

Additionally, the photo-efficiency of the $\mathrm{h}-\mathrm{WO}_{3} \mathrm{NWs}$ was comparable to that of the $\mathrm{m}-\mathrm{WO}_{3} \mathrm{NPs}$ showing similar rate constant values of $1.72 \times 10^{-3} \mathrm{~min}^{-1}$ and $1.79 \times 10^{-3} \mathrm{~min}^{-1}$, respectively. The monoclinic phase $\mathrm{WO}_{3}$ was reported to exhibit higher photo-efficiency relative to hexagonal $\mathrm{WO}_{3}$ due to the more oxidized composition, ${ }^{\mathbf{4 2}}$ which was confirmed by our results when $\mathrm{h}-\mathrm{WO}_{3}$ and $\mathrm{m}-\mathrm{WO}_{3} \mathrm{NPs}$ with similar morphologies were compared. Clearly, beside the prominent effect of the crystal phase, the morphology could play an important role in the determination of the photo-efficiency. The highest photodegradation was presented by the h- $\mathrm{WO}_{3} \quad \mathrm{NW} / \mathrm{TiO}_{2}$ nanocomposite. It decomposed $56 \%$ of the original dye concentration by the end of the 4 hour reaction, which represents a higher than four times improvement relative to the $\mathrm{h}-\mathrm{WO}_{3} \mathrm{NPs}$ and 

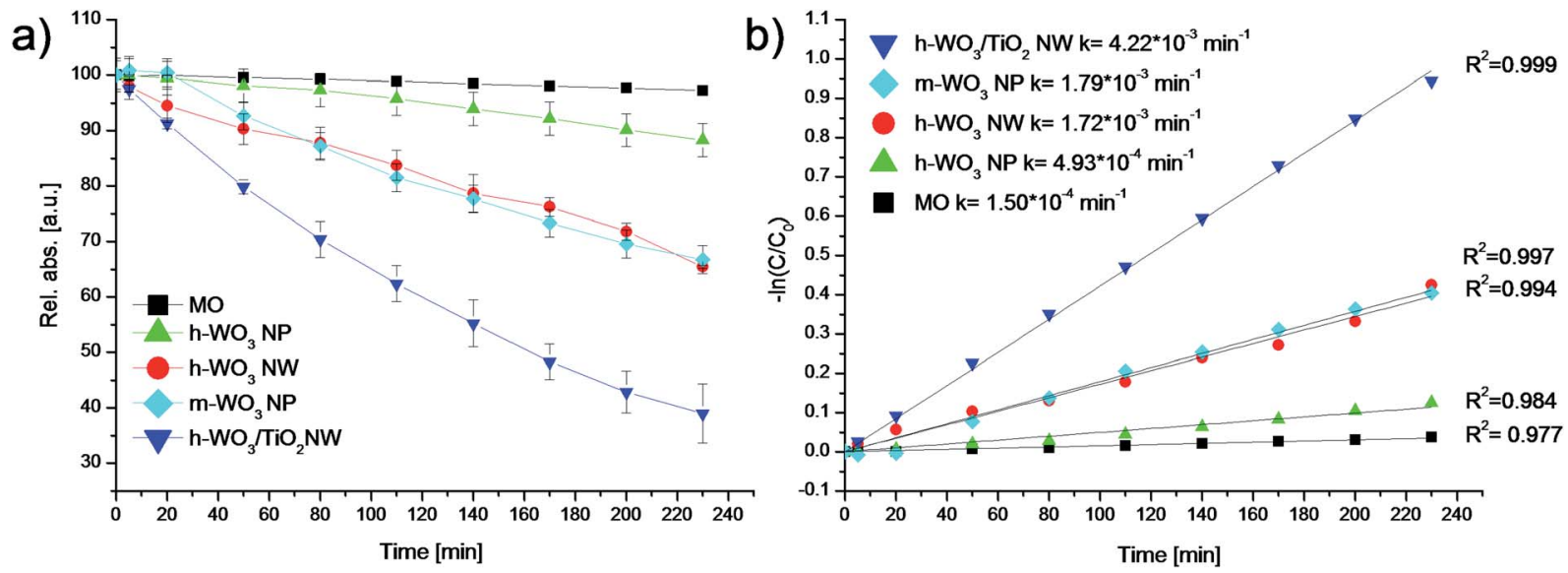

Fig. 6 (a) Photocatalytic degradation curves and (b) linearized first rate kinetic curves of the $\mathrm{m}-\mathrm{WO}_{3} \mathrm{NPs}, \mathrm{h}-\mathrm{WO}_{3} \mathrm{NPs}, \mathrm{h}-\mathrm{WO} \mathrm{O}_{3} \mathrm{NWs}$, and h-WO 3 $\mathrm{TiO}_{2}$ NWs samples.

almost two times better performance relative to the $\mathrm{h}-\mathrm{WO}_{3}$ NWs. Therefore, the highest rate constant of $4.22 \times 10^{-3} \mathrm{~min}^{-1}$ was calculated for the $\mathrm{h}-\mathrm{WO}_{3} \mathrm{NW} / \mathrm{TiO}_{2}$ nanocomposite. The enhanced photoactivity can be attributed to the better light utilization due to absorption in the complete UV-Vis spectrum, and reduced recombination of the photo-generated charges through effective charge separation between $\mathrm{h}-\mathrm{WO}_{3}$ and $\mathrm{TiO}_{2}$. In the literature it was earlier reported that $\mathrm{m}-\mathrm{WO}_{3}-\mathrm{TiO}_{2}$ nanocomposite prepared by depositing $\mathrm{TiO}_{2}$ onto nanofibers of $\mathrm{m}-\mathrm{WO}_{3}$ by ALD showed improved activities relative to bare $\mathrm{WO}_{3}$ and $\mathrm{TiO}_{2} \cdot{ }^{45}$ However, successful ALD reaction onto h- $\mathrm{WO}_{3} \mathrm{NWs}$ to prepare $\mathrm{h}-\mathrm{WO}_{3} \mathrm{NW} / \mathrm{TiO}_{2}$ nanocomposite has not yet been presented to the best of our knowledge. The advantage of coupling $\mathrm{WO}_{3}$ with $\mathrm{TiO}_{2}$ in various crystal phases and morphologies was shown to have a great potential in improving photocatalytic performances. ${ }^{35,76,77}$ This was not straightforward, since previously it was observed that in the case of blue h$\mathrm{WO}_{3}$ samples with partially reduced $\mathrm{W}$ atoms the photocatalytic activity was significantly lower, even compared to yellow $\mathrm{h}-\mathrm{WO}_{3}$ NPs. ${ }^{42}$ The reason could be that although the blue $\mathrm{h}-\mathrm{WO}_{3}$ had absorption in the complete UV-Vis spectrum, this was overcome by that the partially reduced $\mathrm{W}$ atoms served as recombination centers for photo-generated electrons and holes.

Nevertheless, in the case of the $\mathrm{h}-\mathrm{WO}_{3} / \mathrm{TiO}_{2} \mathrm{NW}$ sample, the addition of $\mathrm{TiO}_{2}$ strongly influenced the photocatalytic activity, and resulted in a more effective photocatalyst compared to pure $\mathrm{h}-\mathrm{WO}_{3}$ or $\mathrm{m}-\mathrm{WO}_{3}$. It clearly shows the efficiency of ALD to reprogramme the surface properties of nanostructures by depositing nanolayers or nanoparticles on them, and thus to prepare photocatalysts with superior properties.

\section{Mechanism of photocatalytic activities}

It was revealed that $\mathrm{m}-\mathrm{WO}_{3}$ nanostructures typically overperform $\mathrm{h}-\mathrm{WO}_{3}$ nanostructures. ${ }^{42}$ It is believed that structural differences play a key role in that. Photoluminescence studies (PL) confirmed that although $\mathrm{h}-\mathrm{WO}_{3}$ and $\mathrm{m}-\mathrm{WO}_{3}$ has similar emission pattern, $\mathrm{h}-\mathrm{WO}_{3}$ typically shows lower intensities in the luminescence spectrum. ${ }^{42}$ This was previously attributed to the partially reduced state of $\mathrm{h}-\mathrm{WO}_{3}$ compared to $\mathrm{m}-\mathrm{WO}_{3}$ which arose from the presence of stabilizing cations in its hexagonal crystal structure. Between the reduced $\mathrm{W}$ atoms polaron transition could take place induced by the absorbed light. ${ }^{78}$ Due to this, fewer light portion can actually play role in the excitation of electrons from the valence band to the conduction band of the $\mathrm{h}-\mathrm{WO}_{3}$ which explains the somewhat limited photocatalytic activities of $\mathrm{h}-\mathrm{WO}_{3}$ relative to $\mathrm{m}-\mathrm{WO}_{3}$.

One approach to mitigate $\mathrm{e}^{-}-\mathrm{h}^{+}$pair recombination in single nanostructures is to form heterojunctions. In the event of beneficially aligned energy levels, the photo-generated charges can accumulate on different semiconductors which was found to produce longer-lived charges. ${ }^{26}$ For a $\mathrm{WO}_{3} / \mathrm{TiO}_{2}$ system the electrons would favor to accumulate on the conduction band of $\mathrm{WO}_{3}$ whereas holes would be preferably injected from the valence band of $\mathrm{WO}_{3}$ to the valence band of $\mathrm{TiO}_{2}$. This way the separation of the photo-generated charges can take place which supports photocatalytic surface reactions to take place. PL studies were also applied earlier to confirm the effective chargeseparation in $\mathrm{WO}_{3}-\mathrm{TiO}_{2}$ systems. ${ }^{67}$ It was found that the emission intensities for the nanocomposite versus e.g. $\mathrm{TiO}_{2}$ was much lowered which was explained by the improved charge separation in the nanocomposite material.

\section{Conclusions}

In this paper $\mathrm{h}-\mathrm{WO}_{3}$ has been prepared by controlled annealing of $\left(\mathrm{NH}_{4}\right)_{x} \mathrm{WO}_{3}$ and by microwave hydrothermal synthesis to produce nanoparticles and nanowires, respectively. The two distinct morphologies were tested in photocatalytic application against $\mathrm{m}-\mathrm{WO}_{3}$ nanoparticles prepared also from $\left(\mathrm{NH}_{4}\right)_{x} \mathrm{WO}_{3}$. The $\mathrm{h}-\mathrm{WO}_{3}$ and $\mathrm{m}-\mathrm{WO}_{3}$ NPs were pure and consisted of $50-70$ $\mathrm{nm}$ and $70-90 \mathrm{~nm}$ particles, respectively. The $\mathrm{h}-\mathrm{WO}_{3} \mathrm{NWs}$ were single crystalline, $5-10 \mathrm{~nm}$ thick and several micrometer long. It was found that the $\mathrm{h}-\mathrm{WO}_{3}$ NWs had double as high photocatalytic activity compared to h-WO $\mathrm{W}_{3} \mathrm{NPs}$, and their performance was similar to $\mathrm{m}-\mathrm{WO}_{3} \mathrm{NPs}$. 
The $\mathrm{h}-\mathrm{WO}_{3}$ nanowires were then used as substrates for $\mathrm{TiO}_{2}$ deposition by atomic layer deposition to study the nucleation characteristics of $\mathrm{TiO}_{2}$ on hexagonal phase $\mathrm{WO}_{3}$ for the first time. It was shown that the nucleation on the surface of $\mathrm{h}-\mathrm{WO}_{3}$ was substantially different from that of the $\mathrm{m}-\mathrm{WO}_{3}$. When $\mathrm{TiO}_{2}$ was deposited by $\mathrm{ALD}$ onto $\mathrm{h}-\mathrm{WO}_{3} \mathrm{NWs}$, it did not form a continuous layer as on the surface of $\mathrm{m}-\mathrm{WO}_{3}$, but rather 5$10 \mathrm{~nm}$ particles. The unique nucleation pattern was understood by the lower surface $\mathrm{OH}$ density of $\mathrm{h}-\mathrm{WO}_{3}$ compared to $\mathrm{m}-\mathrm{WO}_{3}$ which did not serve dense enough nucleation sites for the ALD reactions to occur in a continuous manner. It was also presented that in contrast to yellow h-WO $3 \mathrm{NWs}$, the $\mathrm{h}-\mathrm{WO}_{3} / \mathrm{TiO}_{2}$ NW turned to blue, due to the appearance of partially reduced $\mathrm{W}$ atoms. Our study is the first investigation of ALD nucleation on various $\mathrm{WO}_{3}$ polymorphs and also the first example that different crystalline modifications of the same oxide material have so diverse effect on ALD growth.

When $\mathrm{TiO}_{2}$ was grown on $\mathrm{h}-\mathrm{WO}_{3}$ NWs, it significantly increased the photocatalytic degradation rate, and resulted in a $65 \%$ increase in photocatalytic performance. Our results show that ALD is an outstanding tool to prepare composite photocatalysts.

\section{Acknowledgements}

D. Nagy acknowledges the Principal Career Development Scholarship awarded by the University of Edinburgh. I. M. Szilágyi acknowledges a János Bolyai Research Fellowship of the Hungarian Academy of Sciences and an OTKA-PD-109129 grant. Z. Baji, A. L. Tóth are acknowledged for contributing to the ALD depositions, ellipsometry and SEM-EDX measurements (Hungarian Academy of Sciences, Centre for Energy Research, Institute of Technical Physics and Materials Science, Budapest, Hungary).

\section{References}

1 H. Zhu and T. Lian, Energy Environ. Sci., 2012, 5, 9406-9418.

2 R. Das, S. B. A. Hamid, M. E. Ali, A. F. Ismail, M. S. M. Annuar and S. Ramakrishna, Desalination, 2014, 354, 160-179.

3 H. Tong, S. X. Ouyang, Y. P. Bi, N. Umezawa, M. Oshikiri and J. H. Ye, Adv. Mater., 2012, 24, 229-251.

4 J. Byrne, P. Dunlop, J. Hamilton, P. Fernández-Ibáñez, I. Polo-López, P. Sharma and A. Vennard, Molecules, 2015, 20, 5574 .

5 N. Zhou, V. Lopez-Puente, Q. Wang, L. Polavarapu, I. Pastoriza-Santos and Q.-H. Xu, RSC Adv., 2015, 5, 2907629097.

6 W. Wu, J. Changzhong and V. A. L. Roy, Nanoscale, 2015, 7, 38-58.

7 W. Zhong, D. Li, S. Jin, W. Wang and X. Yang, Appl. Surf. Sci., 2015, 356, 1341-1348.

8 S. Yurdakal, V. Loddo, V. Augugliaro, H. Berber, G. Palmisano and L. Palmisano, Catal. Today, 2007, 129, 915.

9 S. Malato, P. Fernández-Ibáñez, M. I. Maldonado, J. Blanco and W. Gernjak, Catal. Today, 2009, 147, 1-59.
10 X. B. Chen, L. Liu, P. Y. Yu and S. S. Mao, Science, 2011, 331, 746-750.

11 G. Halasi, I. Ugrai and F. Solymosi, J. Catal., 2011, 281, 309-317. 12 M. Gratzel, Nature, 2001, 414, 338-344.

13 Q. Gu, J. L. Long, Y. G. Zhou, R. S. Yuan, H. X. Lin and X. X. Wang, J. Catal., 2012, 289, 88-99.

14 A. Fujishima, X. T. Zhang and D. A. Tryk, Surf. Sci. Rep., 2008, 63, 515-582.

15 O. Czakkel, E. Geissler, I. M. Szilágyi and L. Krisztina, 2013, 1, 23-30.

16 S. Banerjee, D. D. Dionysiou and S. C. Pillai, Appl. Catal., B, 2015, 176-177, 396-428.

17 Y. Zhang, Z. Jiang, J. Huang, L. Y. Lim, W. Li, J. Deng, D. Gong, Y. Tang, Y. Lai and Z. Chen, RSC Adv., 2015, 5, 79479-79510.

18 K. Teramura, T. Tanaka, M. Kani, T. Hosokawa and T. Funabiki, J. Mol. Catal. A: Chem., 2004, 208, 299-305.

19 T. Arai, M. Yanagida, Y. Konishi, Y. Iwasaki, H. Sugihara and K. Sayama, Catal. Commun., 2008, 9, 1254-1258.

20 Z.-G. Zhao and M. Miyauchi, Angew. Chem., Int. Ed., 2008, 47, 7051-7055.

21 D. S. Bohle and C. J. Spina, J. Am. Chem. Soc., 2009, 131, 4397-4404.

22 K. Tang, J. Zhang, W. Yan, Z. Li, Y. Wang, W. Yang, Z. Xie, T. Sun and H. Fuchs, J. Am. Chem. Soc., 2008, 130, 2676-2680.

23 G. Panthi, M. Park, H.-Y. Kim, S.-Y. Lee and S.-J. Park, J. Ind. Eng. Chem., 2015, 21, 26-35.

24 W. W. Zhong, Y. F. Lou, S. F. Jin, W. J. Wang and L. W. Guo, Sci. Rep., 2016, 6, 1-7.

25 Z.-F. Huang, J. Song, L. Pan, X. Zhang, L. Wang and J.-J. Zou, Adv. Mater., 2015, 27, 5309-5327.

26 Y. J. Wang, Q. S. Wang, X. Y. Zhan, F. M. Wang, M. Safdar and J. He, Nanoscale, 2013, 5, 8326-8339.

27 R. Bogue, Sens. Rev., 2014, 34, 1-8.

28 D. L. Liao, C. A. Badour and B. Q. Liao, J. Photochem. Photobiol., A, 2008, 194, 11-19.

29 H. Y. Wang, Y. Yang, X. Li, L. J. Li and C. Wang, Chin. Chem. Lett., 2010, 21, 1119-1123.

30 M. R. Gholipour, C.-T. Dinh, F. Beland and T.-O. Do, Nanoscale, 2015, 7, 8187-8208.

31 D. Nagy, D. Nagy, I. M. Szilágyi and X. Fan, RSC Adv., 2016, 6, 33743-33754.

32 F. Amano, E. Ishinaga and A. Yamakata, J. Phys. Chem. C, 2013, 117, 22584-22590.

33 Y. Xia, P. Yang, Y. Sun, Y. Wu, B. Mayers, B. Gates, Y. Yin, F. Kim and H. Yan, Adv. Mater., 2003, 15, 353-389.

34 T. Firkala, B. Fórizs, E. Drotár, A. Tompos, A. Tóth, K. VargaJosepovits, K. László, M. Leskelä and I. M. Szilágyi, Catal. Lett., 2014, 144(5), 831-836.

35 F. Wang, X. Chen, X. Hu, K. S. Wong and J. C. Yu, Sep. Purif. Technol., 2012, 91, 67-72.

36 M. Shu-Quian, Z. De-Feng, Z. Xiao-Fei, Y. Guo-Cheng and L. Zhao-Hui, J. Inorg. Mater., 2014, 29, 605-613.

37 B. Lu, X. Li, T. Wang, E. Xie and Z. Xu, J. Mater. Chem. A, 2013, 1, 3900-3906.

38 P. Guo, L. T. Meng and C. H. Wang, Adv. Mater. Res., 2013, 850-851, 78-81. 
39 E. Kamali Heidari, E. Marzbanrad, C. Zamani and B. Raissi, Nanoscale Res. Lett., 2010, 5, 370-373.

40 H. Long, W. Zeng and H. Zhang, J. Mater. Sci.: Mater. Electron., 2015, 26, 4698-4707.

41 I. M. Szilágyi, E. Santala, M. Heikkilä, M. Kemell, T. Nikitin, L. Khriachtchev, M. Räsänen, M. Ritala and M. Leskelä, J. Therm. Anal. Calorim., 2011, 105, 73-81.

42 I. M. Szilágyi, B. Fórizs, O. Rosseler, Á. Szegedi, P. Németh, P. Király, G. Tárkányi, B. Vajna, K. Varga-Josepovits, K. László, A. L. Tóth, P. Baranyai and M. Leskelä, J. Catal., 2012, 294, 119-127.

43 I. M. Szilágyi, J. Madarász, G. Pokol, P. Király, G. Tárkányi, S. Saukko, J. Mizsei, A. L. Tóth, A. Szabó and K. VargaJosepovits, Chem. Mater., 2008, 20, 4116-4125.

44 A. Phuruangrat, D. J. Ham, S. J. Hong, S. Thongtem and J. S. Lee, J. Mater. Chem., 2010, 20, 1683-1690.

45 I. M. Szilágyi, E. Santala, M. Heikkilä, V. Pore, M. Kemell, T. Nikitin, G. Teucher, T. Firkala, L. Khriachtchev, M. Räsänen, M. Ritala and M. Leskelä, Chem. Vap. Deposition, 2013, 19(4-6), 149-155.

46 V. Miikkulainen, M. Leskela, M. Ritala and R. L. Puurunen, J. Appl. Phys., 2013, 113, 021301.

47 M. N. Liu, X. L. Li, S. K. Karuturi, A. I. Y. Tok and H. J. Fan, Nanoscale, 2012, 4, 1522-1528.

48 I. M. Szilágyi and D. Nagy, J. Phys.: Conf. Ser., 2014, 559, 012010.

49 H. Kim, H. B. R. Lee and W. J. Maeng, Thin Solid Films, 2009, 517, 2563-2580.

50 I. M. Szilágyi, G. Teucher, E. Härkönen, E. Färm, T. Hatanpää, T. Nikiti, L. Khriachtchev, M. Räsänen, M. Ritala and M. Leskelä, Nanotechnology, 2013, 24, 245701.

51 M. Knez, K. Nielsch and L. Niinistö, Adv. Mater., 2007, 19, 3425-3438.

52 S. Boyadjiev, V. Georgieva, L. Vergov, B. Zs, F. Gáber and I. M. Szilágyi, J. Phys.: Conf. Ser., 2014, 559, 012013.

53 I. M. Szilágyi, J. Pfeifer, C. Balázsi, A. L. Tóth, K. VargaJosepovits, J. Madarász and G. Pokol, J. Therm. Anal. Calorim., 2008, 94, 499-505.

54 I. M. Szilágyi, S. Saukko, J. Mizsei, A. L. Tóth, J. Madarász and G. Pokol, Solid State Sci., 2010, 12, 1857-1860.

55 V. B. Patil, P. V. Adhyapak, S. S. Suryavanshi and I. S. Mulla, J. Alloys Compd., 2014, 590, 283-288.

56 T. Peng, D. Ke, J. Xiao, L. Wang, J. Hu and L. Zan, J. Solid State Chem., 2012, 194, 250-256.

57 J. Yu, L. Qi, B. Cheng and X. Zhao, J. Hazard. Mater., 2008, 160, 621-628.

58 D. Hunyadi, A. V. M. Ramos and I. M. Szilágyi, J. Therm. Anal. Calorim., 2015, 120, 209-215.
59 D. Hunyadi, I. Sajó and I. M. Szilágyi, J. Therm. Anal. Calorim., 2014, 116, 329-337.

60 A. Sonia, Y. Djaoued, B. Subramanian, R. Jacques, M. Eric, B. Ralf and B. Achour, Mater. Chem. Phys., 2012, 136, 80-89.

61 I. M. Szilágyi, S. Saukko, J. Mizsei, P. Király, G. Tárkányi, A. Tóth, A. Szabó, K. Varga-Josepovits, J. Madarász and G. Pokol, Mater. Sci. Forum, 2008, 589, 161-165.

62 I. M. Szilágyi, L. Wang, P.-I. Gouma, C. Balázsi, J. Madarász and G. Pokol, Mater. Res. Bull., 2009, 44, 505-508.

63 C. Santato, M. Odziemkowski, M. Ulmann and J. Augustynski, J. Am. Chem. Soc., 2001, 123, 10639-10649.

64 A. Rey, P. García-Muñoz, M. D. Hernández-Alonso, E. Mena, S. García-Rodríguez and F. J. Beltrán, Appl. Catal., B, 2014, 154-155, 274-284.

65 I. M. Szilágyi, I. Sajó, P. Király, G. Tárkányi, A. Tóth, A. Szabó, K. Varga-Josepovits, J. Madarász and G. Pokol, J. Therm. Anal. Calorim., 2009, 98, 707-716.

66 J. Zhang, W. Zhang, Z. Yang, Z. Yu, X. Zhang, T. C. Chang and A. Javey, Sens. Actuators, B, 2014, 202, 708-713.

67 H. Shen, I.-R. Ie, C.-S. Yuan and C.-H. Hung, Appl. Catal., B, 2016, 195, 90-103.

68 D. Nagy, T. Firkala, X. Fan and I. M. Szilágyi, Eur. Chem. Bull., 2016, 5, 40-42.

69 C. S. Hwang and A. Y. Yoo, Atomic Layer Deposition for Semiconductors, Springer, New York, Heidelberg, Dordrecht, London, 2014.

70 N. Pinna and M. Knez, Atomic Layer Deposition of Nanostructured Materials, Wiley-VCH Verlag \& Co. KGaA, Weinheim, Germany, 2011.

71 M. Ritala and M. Leskelä, in Handbook of Thin Films, ed. H. S. Nalwa, Academic Press, Burlington, 2002, pp. 103-159, DOI: 10.1016/B978-012512908-4/50005-9.

72 S. Adhikari and D. Sarkar, RSC Adv., 2014, 4, 20145-20153.

73 J. Su, X. Feng, J. D. Sloppy, L. Guo and C. A. Grimes, Nano Lett., 2010, 11, 203-208.

74 G. Liu, L.-C. Yin, J. Wang, P. Niu, C. Zhen, Y. Xie and H.-M. Cheng, Energy Environ. Sci., 2012, 5, 9603-9610.

75 H. Dong, Z. Wu, F. Lu, Y. Gao, A. El-Shafei, B. Jiao, S. Ning and X. Hou, Nano Energy, 2014, 10, 181-191.

76 J. K. Yang, X. T. Zhang, H. Liu, C. H. Wang, S. P. Liu, P. P. Sun, L. L. Wang and Y. C. Liu, Catal. Today, 2013, 201, 195-202.

77 L. Yang, Z. Si, D. Weng and Y. Yao, Appl. Surf. Sci., 2014, 313, 470-478.

78 S. H. Lee, H. M. Cheong, C. E. Tracy, A. Mascarenhas, D. K. Benson and S. K. Deb, Electrochim. Acta, 1999, 44, 3111-3115. 